\title{
Influence of cavity preparation technique (rotary vs. ultrasonic) on microleakage and marginal fit of six end-root filling materials
}

\author{
Juan-Ignacio Rosales-Leal ${ }^{1}$, Victoria Olmedo-Gaya ${ }^{2}$, Manuel Vallecillo-Capilla ${ }^{3}$, Juan-de-Dios Luna-del \\ Castillo $^{4}$ \\ ${ }^{1}$ DDS, PhD; Contracted Professor, Department of Stomatology, (Dental Prosthetics), University of Granada \\ ${ }^{2}$ DDS, PhD; Assistant Professor, Department of Stomatology (Oral Surgery). University of Granada \\ ${ }^{3}$ DMS, PhD; Associate Professor, Director of Masters in Oral Surgery and Implantology, Department of Stomatology (Oral \\ Surgery), University of Granada \\ ${ }^{4}$ Associate Professor, Department of Statistics, University of Granada
}

Correspondence:

Universidad de Granada,

Facultad de Odontología,

Campus de Cartuja s/n,

18071-Granada (Spain)

irosales@ugr.es

\author{
Rosales-Leal JI, Olmedo-Gaya V, Vallecillo-Capilla M, Luna-del Castillo \\ JD. Influence of cavity preparation technique (rotary vs. ultrasonic) on \\ microleakage and marginal fit of six end-root filling materials. Med Oral \\ Patol Oral Cir Bucal. 2011 Mar 1;16 (2):e185-9. \\ http://www.medicinaoral.com/medoralfree01/v16i2/medoralv16i2p185pdf
}

Received: $22 / 02 / 2010$

Accepted: 26/08/2010

\begin{abstract}
Objectives: To evaluate in vitro the effect of cavity preparation with microburs and diamond-coated ultrasonic tips on the microleakage and marginal fit of six end-root filling materials.

Study Design. The following materials were assessed: amalgam (Amalcap), zinc oxide eugenol (IRM), glass ionomer (Vitrebond), compomer (Cavalite), mineral particle aggregate (MTA) and composite (Clearfil). Cavity preparation was performed with microburs or diamond ultrasonic tips in single-root teeth. The seal was evaluated in two experiments: a microleakage assay on the passage of dye to the interface; and a scanning electron microscopy study and analysis of epoxy resin replicas, measuring the size of gaps in the interface between filling material and cavity walls. Multifactorial ANOVA, multiple comparison test and Student's $t$ test were used for statistical analyses of the data, considering $\mathrm{p}<0.05$ to be significant.

Results: Clearfil and MTA achieved a hermetic seal. Leakage and interface gap size was greater with Cavalite than with Clearfil and MTA, followed by Vitrebond and IRM. The worst seal was obtained with Amalcap. The use of diamond-coated ultrasonic tips improved the seal and reduced the gap when using materials that did not hermetically seal the cavity (Amalcap, IRM, Cavalite, Vitrebond). The preparation technique did not affect materials that achieved a hermetic seal (Clearfil, MTA).

Conclusions: Clearfil and MTA obtained a hermetic seal due to their excellent marginal fit and are the most recommended materials for clinical use, taking account of their sealing capacity. Ultrasonic cavity preparation is preferable because it improves the seal and marginal fit of materials that do not achieve a hermetic seal of the cavity (Amalcap, IRM, Cavalite, Vitrebond).
\end{abstract}

Key words: Periapical surgery, root-end filling material, marginal fit. 


\section{Introduction}

The success of periapical treatments depends to a large extent on the quality of the post-surgical root seal, since a hermetic seal avoids the passage of bacteria to the interface, preventing re-infection of the apex. It is recommended to remove $3 \mathrm{~mm}$ of apex, prepare a cavity and perform root-end filling (1).

Cavity preparation with small burs in a microhandpiece (micro-burs) has some drawbacks for surgeons and patients, since the operative field is very limited and root bevelling is frequently required, which leaves dentine tubules exposed and favours apex re-infection. Furthermore, substantial amounts of bone must be removed to enhance the access of the microbur, increasing the postoperative discomfort of the patient (2). The introduction of ultrasonic instruments for rootend cavity preparation has solved some of these problems $(2,3)$, improving access to the surgical field, avoiding bevelling and producing a cleaner and deeper cavity centred in the root canal $(1,4,5)$. However, there is a risk that the ultrasound energy produces microcracks in the root, compromising the seal and leading to treatment failure $(3,6,7)$.

Numerous materials have been used for root-end fillings (amalgam, glass-ionomers, zinc-eugenol oxide, and composites or aggregates of mineral particles) (1), but none are universally used as the material of choice. Moreover, insufficient data are available on the influence of the cavity preparation on the seal of the filling material to allow a clear conclusion to be drawn (7). Some authors reported that the cavity preparation had no effect on the seal $(4,8)$, whereas others found it to have a major influence $(3,7)$, and further research is required to elucidate this issue.

The objective of this study was to assess in vitro the effect of cavity preparation with microburs and diamond-coated ultrasonic tips on the microleakage and marginal fit of six root-end filling materials. The null hypothesis was that the preparation technique has no effect on the seal of the filling material.

\section{Material and Methods}

\section{Specimen and retrograde cavity preparations}

Root canal therapy was carried out in 120 anterior singleroot teeth, followed by an apicoectomy, removing $3 \mathrm{~mm}$ of the apex by cutting at $90^{\circ}$ to the long axis of the root, with no bevelling, using a fissure bur in a high-speed handpiece with abundant water-cooling. The prepared specimens were divided between two groups (60 teeth per group). In one group, the cavities were prepared with a rotary technique, using a micromotor with microhead and conical microburs (Kavo, Biberach, Germany). The cavity size (depth of $3 \mathrm{~mm}$, diameter of $1.5 \mathrm{~mm}$ ) was the same in both groups to avoid any influence of this factor on the seal.
Once the cavities were prepared, specimens in each group were randomly divided into 6 subgroups of 10 specimens as a function of the filling material to be applied: amalgam (Amalcap, Vivadent, Liechtenstein) (capsule vibrated for $8 \mathrm{sec}$ ); zinc oxide eugenol (IRM, Dentsply, Konsztanz, Germany) (5 $\mathrm{mg}$ of powder/ml of liquid); resin-reinforced glass ionomer (Vitrebond, 3M, St. Paul, MN, USA) (1 spoon of powder mixed with drop of liquid and light-cured for $40 \mathrm{sec}$ ); compomer (Cavalite, Kerr, Rastatt, Germany) (placed directly in cavity and light cured for $40 \mathrm{sec}$ ); mineral trioxide aggregate (MTA, Dentsply, Konstanz, Germany) (mixture of powder with distilled water); or composite (Clearfil AP, Kuraray, Osaka, Japan) (light-cured for $40 \mathrm{sec}$ ) with self-etching adhesive (Cearfil SE Bond, Kuraray, Osaka, Japan) (self-etched for $20 \mathrm{sec}$ and lightcured for $20 \mathrm{sec}$ ). After the apical filling, all specimens were wrapped in wet gauze and stored in a closed receptacle at $100 \%$ relative humidity and $37^{\circ} \mathrm{C}$ for 24 hours.

Microleakage test

Specimens were removed from the hermetic receptacle and coated with two layers of nail polish, leaving the apicoectomy area uncoated. Roots were then immersed in $0.5 \%$ basic fuchsine water solution for 24 hours, after which they were cleaned and embedded in self-curing acrylic resin. Embedded specimens were sectioned along their long axis under constant water irrigation, producing two slices of 1-mm thickness per specimen in which the filling cavity and two of its walls could be seen. Twenty slices were obtained for each material and each cavity preparation and were analyzed under a reflecting microscope by an experienced examiner blinded to the group to which the specimen belonged. Measurements were made on the two sides of the cavity in each slice, and the microleakage was quantified (in microns) as the penetration of the dye between cavity wall and filling material.

\section{Evaluation of marginal fit}

Six slices were selected for each filling material and each cavity preparation for assessment of the marginal fit by scanning electron microscopy (SEM). Surfaces of the slices were metallographically polished using polishing papers and alumina slurries. In order to avoid interface damage from dehydration during specimen processing, epoxy resin replicas were created after taking impressions of the polished surfaces with polyvinylsiloxane. The resin replica was kept in a $37^{\circ} \mathrm{C}$ oven overnight and then gold sputter-coated and examined under SEM, assessing the interface and measuring the thickness of any gap between the material and cavity walls. Measurements (in microns) were taken on the two cavity walls in each slice at 1 $\mathrm{mm}$ outside the cavity (total of 12 measurements per material and preparation technique). 


\section{Statistical analysis}

Microleakage and interface gap data were analyzed with two-way ANOVA test (analysis factors: preparation technique and material; dependent variables: microleakage and interface gap) and the Student-Newman-Keuls test for multiple comparisons. The Student's t test was used to compare differences in microleakage and interface gap measurements between cavities prepared with rotary and ultrasonic instruments. $\mathrm{P}<0.05$ was considered significant.

\section{Results}

The microleakage data are shown in (Table 1). The influence of the cavity preparation was significant when Amalcap, Cavalite and Vitrebond were used as filling materials, obtaining lower leakage values in cavities prepared with ultrasonic tips, but not when IRM, MTA or Clearfil were used. Leakage was influenced by the material used. In the microbur-prepared cavities, leakage was highest with amalgam, followed by IRM, Vibrebond and Cavalite, and it was lowest with MTA and Clearfil. In the ultrasonically-prepared cavities, leakage was highest with Amalcap, followed by IRM and Vitrebond, and it was lowest with MTA, Clearfil and Cavalite.

The SEM images in figure 1 show the interfaces obtained with the different materials, and table 1 gives the interface gap data. The interface appears relatively rectilinear in microbur-prepared cavities (Figs. 1A and 1D) but undulating in ultrasonic tip-prepared cavities (Figs. 1B and 1C). No cracks were observed in the dentin of any of the specimens evaluated. Examination of the fit of the material to cavity walls showed: a continuous gap at the interface using Amalcap (Fig. 1E) and IRM (Figs. $1 \mathrm{~A}$ and $1 \mathrm{~B}$ ); areas with gaps (Fig. 1F) and areas without gaps $(1 \mathrm{G})$ using Vitrebond and Cavalite; and interface with no gaps using MTA (Figs. 1C and 1D) and Clearfil
(Fig. 1H). The gap size was smaller in ultrasonicallyprepared cavities filled with Amalcap, IRM, Vitrebond or Cavalite. The smallest interface gap was observed with MTA and Clearfil, followed by Cavalite, Vitrebond (with ultrasonic preparation), Amalcap and Vitrebond (with microburs). The largest gap was observed when IRM was used.

\section{Discussion}

In this study, the sealing ability of some root-end filling materials was influenced by the apical preparation technique used, largely attributable to the different surface irregularities produced by the two methods. Surfaces prepared with carbide burs are known to be less rough than those prepared with diamond-coated ultrasonic tips $(9,10)$, as demonstrated in our SEM images (Figs. 1A vs.1B and $1 \mathrm{C}$ vs. 1D). A rougher and hence more irregular surface offers a greater contact surface area, improving the retention and stability of the filling material. The chemical reaction of setting or light-curing is associated with volumetric variations $(11,12)$; hence, the presence of greater irregularities in cavities prepared with diamond-coated ultrasonic tips favours the retention (11) and stability of the material at the interface during the chemical reaction, reducing the risk of interface gaps and the resulting microleakage. The SEM findings confirmed this effect, showing a smaller gap in the ultrasonic tip-prepared (Figs. 1B and $1 \mathrm{C}$ ) versus microbur-prepared (Figs. 1A and 1D) cavities.

The condition of the cavity surface is another influential factor to be considered. It has been demonstrated that cavities prepared with rotary instruments are left with a greater amount of debris and smear layer in comparison to those prepared with diamond-coated ultrasonic tips $(4,5)$. These remains are permeable and (13) allow microleakage, preventing complete contact

Table 1. Microleakage and interface gap size in cavities filled with different materials and prepared with microburs or diamond-coated ultrasonic tips.

\begin{tabular}{|l|c|c|c|c|}
\hline \multirow{2}{*}{ Filling material } & \multicolumn{2}{|c|}{$\begin{array}{c}\text { Microleakage }(\mu \mathrm{m}) \\
\text { Mean (SD) }\end{array}$} & \multicolumn{2}{c|}{$\begin{array}{c}\text { Gap size }(\mu \mathrm{m}) \\
\text { Mean }(\text { SD) }\end{array}$} \\
\cline { 2 - 5 } & Microburs & $\begin{array}{c}\text { Diamond-coated } \\
\text { ultrasonic tips }\end{array}$ & Microburs & $\begin{array}{c}\text { Diamond-coated } \\
\text { ultrasonic tips }\end{array}$ \\
\hline Amalcap & $3300(1019)^{\mathrm{e}}$ & $1878(884)^{\mathrm{d}}$ & $3.7(1.2)^{\mathrm{i}}$ & $2.4(1.3)^{\mathrm{h}}$ \\
IRM & $1253(1022)^{\mathrm{c}}$ & $1183(563)^{\mathrm{c}}$ & $15(4)^{\mathrm{k}}$ & $8(3)^{\mathrm{j}}$ \\
Vitrebond & $958(266)^{\mathrm{c}}$ & $650(388)^{\mathrm{b}}$ & $4.6(2.6)^{\mathrm{i}}$ & $2.5(1.6)^{\mathrm{h}}$ \\
Cavalite & $500(470)^{\mathrm{b}}$ & $35(134)^{\mathrm{a}}$ & $1.3(0.9)^{\mathrm{g}}$ & $0.7(0.7)^{\mathrm{f}}$ \\
MTA & $25(112)^{\mathrm{a}}$ & $20(84)^{\mathrm{a}}$ & $0.1(0.1)^{\mathrm{e}}$ & $0.1(0.1)^{\mathrm{e}}$ \\
Clearfil & $10(30)^{\mathrm{a}}$ & $13(59)^{\mathrm{a}}$ & $0.6(0.3)^{\mathrm{ef}}$ & $0.5(0.4)^{\mathrm{ef}}$ \\
\hline
\end{tabular}

Values with the same letter are not significantly different $(p>0.05)$. Letters a to e indicate significant differences in microleakage. Letters $\mathrm{f}$ to $\mathrm{i}$ indicate significant differences in gap size. The order of the letters expresses the degree of micro leakage or gap size (SD: standard deviation). 

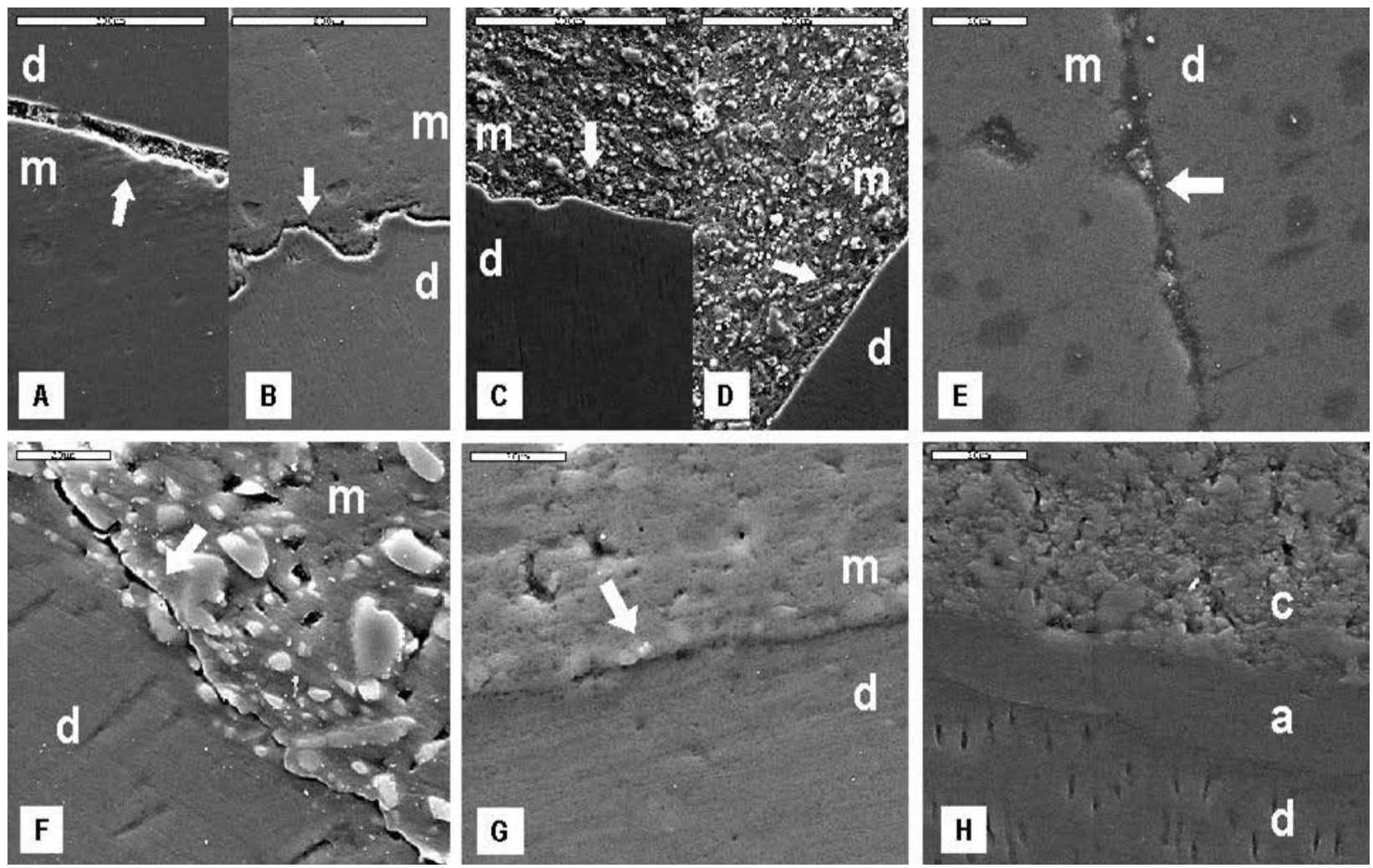

Fig. 1. SEM micrographs of the tested materials. (A and D) Interface line in cavities prepared with microburs (x300); the interface is rectilinear. (B and C) Interface line in a cavity prepared with diamond-coated ultrasonic tips (x300); the interface line is undulating and irregular. IRM was used in (A) and (B), showing gaps in the interface (arrow) and the difference in gap size between (A) and (B); ultrasonic preparation produced a smaller gap size (B) in comparison to microbur preparation (A). MTA was used in (C) and (D), and no differences were observed as a function of the preparation technique because the material achieved a gap-free interface in both cases. (E) Amalcap in ultrasonic tip-prepared cavity (x1000) shows a gap (arrow) along the entire interface. (F) Vitrebond in microbur-prepared cavity (x1000) shows an interface with gaps (arrow) in some areas. (G) Cavalite in ultrasonic tip-prepared cavity (x1000) shows some gap-free areas in the interface (arrow). (H) Clearfil in a microbur-prepared cavity shows a gap-free hermetic seal (x1000). [d: dentin; m: filling material; c: composite; a: adhesive].

between filling material and cavity walls (2). A greater presence of this layer in microbur-prepared cavities helps to explain the greater leakage observed with some materials in microbur- versus ultrasonic tip-prepared cavities.

As noted in the Introduction, some authors have associated ultrasonic preparations with a higher risk of microcracks in the root $(6,7)$. However, the generation of cracks is related to the intensity of the ultrasonic device, and no dentin tissue damage is produced at the low intensity used in the present study $(5,6,9)$, as confirmed by the failure to detect cracks under SEM (Fig. 1). Furthermore, microleakage values were not higher in ultrasonically prepared specimens than in those prepared with microburs.

The ultrasonic preparation did not achieve a better seal in all cases, only when the material itself did not achieve an adequate seal and showed leakage or interface gaps with the rotary technique (Amalcap, IRM, Vitrebond or Cavalite) (Table 1). In the case of IRM, only a non-significant reduction in microleakage was observed with the ultrasonic technique, but there was a significant reduction in the interface gap and consequent improvement in the fit of the material. When the cavity is hermetically sealed by the material (MTA or Clearfil), the seal cannot be influenced by the technique because the material itself adequately seals the interface. The quality of the seal varied as a function of the material used and was worst (greatest leakage) with Amalcap, as previously reported $(14,15)$. Amalgam showed an initial increase in filtration due to volume changes during its setting (16), which produced a continuous gap along the length of the interface (Fig. 1E). An inadequate seal was also obtained using IRM, as previously reported $(15,9)$,with the presence of gaps in the interface (Figs. 1A and 1B). However, this initial leakage may be advantageous, hydrolyzing the zinc chelate and releasing the eugenol and zinc ions, since the release of eugenol plays a major role in bacterial control (14). The clinical selection of IRM may be based more on this biological property than on its sealing capacity. Vitrebond is a resin-reinforced glass ionomer 
cement that generates a similar acid-base reaction to that observed with conventional ionomers (17) but achieves a better seal because the addition of resin makes the material more resistant to humidity (18). Nevertheless, Vitrebond did not achieve a hermetic seal (Fig. 1F) and, despite the protection of the polymeric matrix, the acid-base reaction lasted for several hours and the final setting may have been affected by humidity.

Cavalite is a flowable compomer that hermetically sealed the cavity in some areas (Fig. 1G) but showed gaps in others, permitting passage of the dye. This material is similar to glass ionomers and composite (it is a polyacid-modified composite) (17). The greater resin content does not allow an acid-base reaction to take place and only a polymerisation is produced (17). The polymeric nature of the material avoids sensitivity to humidity and explains the superior seal obtained in comparison to the resin-reinforced ionomer (Vitrebond). However, this greater polymeric content increases the risk of gap formation and consequent leakage due to polymerisation shrinkage $(13,14)$.

MTA is a mineral aggregate composed of tricalcium silicate, tricalcium alumnate, tricalcium oxide and silicate oxide (11). This material obtains excellent outcomes because it expands (hygroscopic expansion) during setting in the presence of humidity (11), thereby hermetically sealing the interface, and no gaps were visible on the SEM images (Figs. 1C and 1D). Other authors consider MTA to be the material of choice because of the quality of sealing obtained in comparison to amalgam, IRM and other materials $(14,15,19)$.

Novel adhesive systems have shown applications and benefits in periapical surgery. The adhesive interacts with the substrate and achieves a virtually hermetic seal at the interface. Self-etching systems dissolve the smear layer and react with the dentin, forming a hybrid layer (20) and producing a gap-free interface (Fig. 1H) and superior sealing capacity, as previously reported (15).

In conclusion, the most recommendable materials are Clearfil and MTA, which produce an adequate marginal fit and hermetic seal. When using a material that does not achieve a hermetic seal (Amalcap, IRM, Cavalite, Vitrebond), preparation of the cavity with diamondcoated ultrasonic tips is indicated to improve the seal and marginal fit. Therefore, the null hypothesis of this study is refuted.

\section{References References with links to Crossref-DOI}

1. Martí Bowen E, Peñarrocha M. An update in periapical surgery. Med Oral Patol Oral Cir Bucal. 2006;11:E503-9.

2. Von Arx T, Walker WA 3rd. Microsurgical instruments for rootend cavity preparation following apicoectomy: a literature review. Endod Dent Traumatol. 2000;16:47-62.

3. Khabbaz MG, Kerezoudis NP, Aroni E, Tsatsas V. Evaluation of different methods for the root-end cavity preparation. Oral Surg Oral Med Oral Pathol Oral Radiol Endod. 2004;98:237-42.

4. Ishikawa H, Sawada N, Kobayashi C, Suda H. Evaluation of root-end cavity preparation using ultrasonic retrotips. Int Endod J. 2003;36:586-90.

5. Bernardes RA, de Moraes IG, Garcia RB, Bernardineli N, Baldi JV, Victorino FR, et al. Evaluation of apical cavity preparation with a new type of ultrasonic diamond tip. J Endod. 2007;33:484-7.

6. Layton CA, Marshall JG, Morgan LA, Baumgartner JC. Evaluation of cracks associated with ultrasonic root-end preparation. J Endod. 1996;22:157-60

7. De Bruyne MA, De Moor RJ. Influence of cracks on leakage and obturation efficiency of root-end filling materials after ultrasonic preparation: an in vitro evaluation. Quintessence Int. 2008;39:68592.

8. Rainwater A, Jeansonne BG, Sarkar N. Effects of ultrasonic rootend preparation on microcrack formation and leakage. J Endod. 2000;26:72-5.

9. Pioch T, García-Godoy F, Duschner H, Koch MJ, Staehle HJ, Dörfer CE. Effect of cavity preparation instruments (oscillating or rotating) on the composite-dentin interface in primary teeth. Dent Mater. 2003;19:259-63.

10. Ayad MF, Johnston WM, Rosenstiel SF. Influence of dental rotary instruments on the roughness and wettability of human dentin surfaces. J Prosthet Dent. 2009;102:81-8.

11. Torabinejad M, Hong CU, McDonald F, Pitt Ford TR. Physical and chemical properties of a new root-end filling material. J Endod. 1995;21:349-53.

12. Braga RR, Ballester RY, Ferracane JL. Factors involved in the development of polymerization shrinkage stress in resin-composites: a systematic review. Dent Mater. 2005;21:962-70.

13. Prati C, Ferrieri P, Galloni C, Mongiorgi R, Davidson CL. Dentine permeability and bond quality as affected by new bonding systems. J Dent. 1995;23:217-26.

14. Adamo HL, Buruiana R, Schertzer L, Boylan RJ. A comparison of MTA, Super-EBA, composite and amalgam as root-end filling materials using a bacterial microleakage model. Int Endod J. 1999;32:197-203.

15. Torabinejad M, Smith PW, Kettering JD, Pitt Ford TR. Comparative investigation of marginal adaptation of mineral trioxide aggregate and other commonly used root-end filling materials. J Endod. 1995;21:295-9.

16. Okabe T, Mitchell RJ. Setting reactions in dental amalgam. Part 2. The kinetics of amalgamation. Crit Rev Oral Biol Med. 1996;7:2335 .

17. Nicholson JW, Czarnecka B. Review paper: Role of aluminum in glass-ionomer dental cements and its biological effects. J Biomater Appl. 2009;24:293-308.

18. Rosales JI, Vallecillo M, Osorio R, Bravo M, Toledano M. An in vitro comparison of micro leakage in three glass ionomer cements used as retrograde filling materials. Int Dent J. 1996;46:15-21.

19. Wu MK, Kontakiotis EG, Wesselink PR. Long-term seal provided by some root-end filling materials. J Endod. 1998;24:557-60.

20. Tay FR, Pashley DH. Aggressiveness of contemporary selfetching systems. I: Depth of penetration beyond dentin smear layers. Dent Mater. 2001;17:296-308.

\section{Acknowledgements}

The authors are grateful to Yudi Gómez Villaescusa for her laboratory work. The study was funded by grants from the Surgery Research Group of Granada University (CT-245) and the Spanish Ministry of Science and Innovation (project MAT2007-66117). 